Derecho y Realidad

Vol.14 - Núm. 28• julio - diciembre de 2016

Pázs. 155-180 · ISSN:1692-3936

\title{
El escenario para la asistencia y protección a víctimas de trata de personas en Colombia*
}

\author{
Scenario for Assistance and Protection of \\ Human Trafficking Victims in Colombia
}

Nancy Edith Alarcón Moreno**

\section{Resumen}

A través de entrevistas semiestructuradas a organizaciones de la sociedad civil y a una persona que ha vivido la trata laboral, este artículo evidencia los logros o deficiencias del Estado para garantizar el restablecimiento de derechos de las víctimas de trata de personas. Con los resultados hallados se pudo corroborar que la atención y protección a las personas víctimas de trata es tardía o insuficiente y que no hay lineamientos y protocolos para la asistencia y protección de las personas que han experimentado otras formas de explotación diferentes a la explotación sexual.

Fecha de recepción: 03 de agosto de 2016.

Fecha de aprobación: 28 de septiembre de 2016.

* Este artículo hace parte del trabajo de grado "Asistencia y protección a víctimas de trata de personas en Colombia" para optar al título de Magíster en Derechos Humanos de la Universidad Pedagógica y Tecnológica de Colombia, sede Bogotá, año 2016.

** Abogada de la Universidad Autónoma de Colombia, Estudiante de Maestría en Derechos Humanos de la Universidad Pedagógica y Tecnológica de Colombia. correo electrónico: nancy.alarconmoreno@ gmail.com. Bogotá-Colombia 
Además, aunque en Colombia se cuenta con instrumentos normativos para contrarrestar la trata de seres humanos, tan solo hay datos estimativos sobre el número de víctimas, y la política pública está orientada mayormente desde el enfoque criminal, dejando en un segundo lugar los derechos de las víctimas.

Palabras clave: víctimas, trata de personas, asistencia, protección, trabajos forzados.

\section{Abstract}

Through semi-structured interviews with civil society organizations and a person who was a victim of forced labor this article evidences the achievements or deficiencies of the State to guarantee the restoration of the rights of victims of trafficking in persons. The results of this study corroborate that the assistance and protection of victims is insufficient or comes too late and there are no clear guidelines and protocols to assist and protect people who have experienced other forms of exploitation different from sexual exploitation.

Besides, although there are normative instruments in Colombia to combat this crime, there is only an estimative data on the number of victims, and the public policy is mostly oriented from a criminal approach, leaving on a second place the rights of victims.

Keywords: victims, trafficking in persons, assistance, protection, forced labor. 


\section{Introducción}

El delito de la trata de personas es una práctica aterradora e inenarrable, en la que se cosifica al ser humano; además de ser una consecuencia del desmesurado deseo de adquirir capital. Según la Organización Internacional del Trabajo (OIT), citada por el Departamento de Estado de los Estados Unidos (2014), las víctimas de este delito han generado para los tratantes, por año, la suma de 150 millones de dólares.

El Informe del Departamento de Estado (2016), considera que solamente en el año 2015 hubo 77.823 víctimas en el mundo, 33.361 (43\%) más que en el 2014; estas cifras tan solo son la punta del iceberg, debido a que la mayoría de víctimas prefieren no denunciar porque temen represalias de los tratantes.

En Colombia, pese a que se ha ratificado, a través de la Ley 800 de 2003, la Convención de las Naciones Unidas contra la Delincuencia Organizada Transnacional y el Protocolo para Prevenir, Reprimir y Sancionar la Trata de Personas, especialmente Mujeres y Niños, que complementa la Convención de las Naciones Unidas contra la Delincuencia Organizada Transnacional, y que se cuenta con la Ley 985 de 2005, mediante la cual se establecen medidas tanto para contrarrestar este delito como para la asistencia y protección a víctimas, no hay certeza en el número de víctimas de trata en Colombia debido a la existencia de un alto índice de subregistro. Según el Ministerio del Interior, Dirección de Gobierno y Gestión Territorial (2015), del 2011 hasta mediados del 2015 se presentaron 219 personas víctimas de trata ${ }^{1}$. No obstante, la Fiscalía General de la Nación (2015), entre febrero 2014 y febrero 2015 afirman que hubo en curso 305 procesos por este delito, con 495 personas víctimas de trata transnacional, por lo que muchas víctimas son invisibles para el Estado.

Con la intención de contar con una política de Estado para contrarrestar este delito, Colombia adoptó una Estrategia Nacional Integral contra la Trata de Personas por el periodo 2007-2012, mediante Decreto 4786 de 2008. Luego, con el Decreto 1036 de 2016 acogió la Estrategia para la Lucha contra la Trata de Personas 20162018. Empero, como se puede observar, por tres años consecutivos no se tuvo una política pública clara para el tratamiento de la trata de personas.

1 Respuesta a derecho de petición de Corporación Tamar, organización de la sociedad civil que desde 2014 ha enfatizado en la prevención de la trata de personas en Colombia; perteneciente a la Alianza Colombiana de Organizaciones de la Sociedad Civil contra la Trata de Personas y el Capítulo Colombia del Observatorio Latinoamericano sobre Trata y Tráfico de Personas (ObservaLaTrata). 
Además, tan solo hasta finales del mes de agosto del 2016, la Corte Constitucional con la Sentencia C-470 de 2016 declaró inexequible el parágrafo 1 del artículo 7 de la Ley 985 de 2005, mediante el cual se condicionaba la asistencia mediata a la denuncia; situación que se vivió por casi once años, vulnerando los derechos de las víctimas.

Teniendo en cuenta este escenario, la intención de este documento es visibilizar los logros o deficiencias del Estado para asistir y proteger a víctimas (adultas) especialmente de trata laboral, teniendo en cuenta la Estrategia Nacional de Lucha contra la Trata de Personas 2007-2012 y 2016-2018.

Inicialmente, en este artículo se presenta una reflexión en torno a la conceptualización de la trata laboral y sus implicaciones, luego se muestran las diferentes percepciones frente al deber del Estado de asistir y proteger a las víctimas de trata en Colombia y finalmente se exponen algunas conclusiones teniendo en cuenta los resultados obtenidos.

\section{Metodología}

Esta investigación se desarrolló con base en el enfoque cualitativo, utilizando herramientas como la revisión documental y las entrevistas semiestructuradas dirigidas a representantes de organizaciones de la sociedad civil y a una persona que ha sobrevivido a la trata laboral, con el fin de establecer si existen deficiencias en las políticas públicas para la efectiva atención de las víctimas de trata de personas, especialmente por trabajos forzados.

\section{Reflexiones sobre la definición de trata laboral}

Ya en la introducción se mencionaba qué es la trata de personas según el Protocolo para prevenir, reprimir y sancionar la trata de personas especialmente en mujeres y niños ${ }^{2}$. En este sentido, trata se refiere al comercio o mercantilización del ser humano; es decir, que dos características de esta son el traslado y la finalidad de sacarle provecho o recibir beneficios a costa de la explotación de la persona. Tanto el Protocolo de Palermo como la Ley 985 de 2005 determinan algunas de las finalidades: la explotación en la prostitución, u otras formas de explotación sexual, trabajos o servicios forzados, servidumbre, extracción de órganos, entre otras.

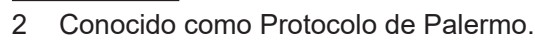


En este caso, para referirse a la trata laboral se utilizan como sinónimos la trata con fines de trabajos forzados o forzosos y la trata con fines de explotación laboral; no obstante, para muchos, esto puede acarrear dificultades por lo que se vacía de contenido a los términos.

El Convenio sobre el Trabajo Forzoso de la Organización Internacional del Trabajo -OIT- en su artículo 2 lo define como "todo trabajo o servicio exigido a un individuo bajo la amenaza de una pena cualquiera y para el cual dicho individuo no se ofrece voluntariamente".

En esta definición, como "trabajo o servicio" se entiende el desarrollo de cualquier actividad que pueda generar bienes o servicios, exigido a cualquier persona, sea mayor o menor de edad, "bajo una pena cualquiera"; es decir, que la actividad se cumple a través de la coacción, constreñimiento o amenaza, lo que implica una restricción a los derechos de la persona; y ella no se ofrece voluntariamente, es decir, que la persona no tuvo la capacidad o las condiciones para decidir libremente. Ahora bien, referirse a trata por trabajos forzosos supone el traslado de la persona a otro lugar dentro o fuera del país.

Para el caso de Colombia, el consentimiento dado por la víctima es irrelevante para configurarse el delito de trata de personas, lo cual riñe con la definición de la OIT, ya que se podría concluir que si la persona consiente la realización de esa labor, no se consideraría trabajo forzado.

Al referirse a trata con fines de explotación laboral, deben tenerse en cuenta sus características (traslado, limitación de movimiento, etc.); igualmente, no toda explotación laboral es trata de personas; algunas situaciones de explotación laboral son controversias dentro del derecho laboral, como por ejemplo las excesivas horas de trabajo o la falta de remuneración.

[...] No hay una conceptualización sólida sobre la explotación laboral y en qué se diferencia de la explotación laboral propiamente dicha [...] la legislación sigue siendo débil (...) nunca elevó al Código Penal tipos autónomos de trabajos forzados y esclavitud [...] es un tema a desarrollarse y que todavía sigue siendo débil [...] no habido una fuerte estrategia de la política pública sobre el tema de trata con fines de explotación laboral [...]. (O. Gómez, comunicación personal, 24 de septiembre de 2016).

En suma, estos dos conceptos han generado controversias, como lo evidencia Gómez (2016) en su entrevista, 
El tema de trata con fines de explotación laboral no se puede reducir [...] a la definición formal de trabajo, porque la trata habla del concepto de explotación y obviamente lo que se explota puede ser el trabajo, el cuerpo, o la imagen o la sexualidad...entonces el concepto de explotación en trata es mucho más que el trabajo, tampoco quiere decir que sean antagónicos porque generalmente cuando a una persona la esclavizan, la esclavizan no es para tenerla encerrada sino que la esclavizan para explotarla ...en el trabajo forzado lo que básicamente se vulnera es la autonomía [...], en la esclavitud lo que afecta es la libertad y obviamente la autonomía, entonces tú puedes subsumir trabajos forzados en esclavitud, pero no puedes subsumir esclavitud en trabajos forzados... Por otro lado, esto implicaría un retroceso en una conquista de derechos humanos... en la definición del tipo penal colombiano... se suprimieron los medios (engaño, amenaza, uso de la fuerza, coacción...) y eso se hizo para que la carga de la prueba no estuviera a cargo de la víctima. Si acoges la definición de trabajos forzados [...] tendría que modificarse el tipo penal incluyendo los medios y esto sería un retroceso que sería inadmisible. (Gómez, 2016).

En este sentido, aún hay que tener en cuenta muchos aspectos para llegar a una definición que abarque o delimite la trata laboral. Sin embargo, esta investigación se referirá a trata de personas con fines de trabajos o servicios forzados, por cuanto es esta la que actualmente contempla la legislación.

Aunque vale la pena aclarar que la explotación es la finalidad de la trata de personas; es decir, como se mencionaba anteriormente, el ser humano es visto como un objeto de comercio que representa innumerables ganancias para sus explotadores. Desafortunadamente, actualmente con la precarización laboral, la pobreza y la acumulación de capital de las grandes multinacionales y la permisividad de los Estados, se está facilitando la trata de personas en trabajos o servicios forzados.

Aunque la trata de personas se encuentra en muchas ramas, el riesgo es más pronunciado en las industrias que dependen de la mano de obra poco calificada y no calificada. Esto comprende trabajos sucios, peligrosos y difíciles, aquellos que generalmente son mal remunerados o subestimados por la sociedad y que a menudo se cubren con grupos de personas socialmente marginadas, incluidos los migrantes, las personas con discapacidades y las minorías. (Departamento de Estado, 2015, pp.7-8).

Por lo cual, no es posible referirse a dignidad humana cuando la persona ha sido sometida a toda clase de vejámenes, donde el "otro", el detentador del poder se 
apropia de todo su ser, explota e instrumentaliza al más débil, como si fuera un objeto de su propiedad, del cual puede disponer a su arbitrio.

Los actos de sevicia y crueldad, los crímenes contra la vida y la reducción a la condición de esclavos constituyen las violaciones más patentes del respeto debido a las personas [...] abstenerse del recurso de la violencia y controlar la tendencia a reducir al otro a simple objeto o mercancía es necesario pero insuficiente para el respeto debido a la persona moral que exige por igual su reconocimiento como un sujeto de necesidades que merecen ser atendidas con concepciones de mundo e ideales... y un ser humano con proyectos vitales. (Papacchini, 1998, pp. 13-14).

Conviene subrayar que ser digno es tener la posibilidad de emanciparse tanto de espíritu como de cuerpo. Por tal razón, la persona víctima de trata tiene el derecho y la obligación misma de reconocer su autonomía, exigir la reivindicación de su condición como sujeto con capacidad de autodeterminación. Esto significa rescatar su capacidad creativa y su memoria, que se le permita desarrollar procesos de emancipación y libertad con la valoración de la diferencia y la posibilidad de un "nosotros".

Por todo lo expuesto, con el objetivo de visualizar cómo el Estado está asistiendo y protegiendo a las víctimas de trata para que puedan retomar su proyecto de vida y evitar que vuelvan a caer en la trata, en primer lugar, se recabó información del Estado, en el ámbito nacional, con el Ministerio del Interior, en la Secretaría Técnica del Comité Interinstitucional de Lucha contra la Trata de Personas, y en el nivel local, en la Secretaría de Gobierno de la Alcaldía Mayor de Bogotá. En segundo lugar, se entrevistó a un experto (quien pidió conservar su identidad en el anonimato) y a cinco representantes de aquellas organizaciones que atienden a personas que han vivido la trata (Fundación Marcela Loaiza: Organización creada por una sobreviviente de trata, Fundación Esperanza, Fundación Jhonatan, Corporación Espacios de Mujer, Corporación Anne Frank) y en tercer lugar, se entrevistó a una persona que por año y medio fue víctima de trata laboral.

\section{Resultados y discusión}

A continuación se presentan los resultados en cuanto a cómo se está asistiendo y protegiendo a las víctimas de trata de personas en Colombia. Con el fin de tener claridad con respecto al tipo de asistencia y protección que el Estado está obligado a garantizar a las personas que han sido víctimas de trata, se presenta el siguiente diagrama: 


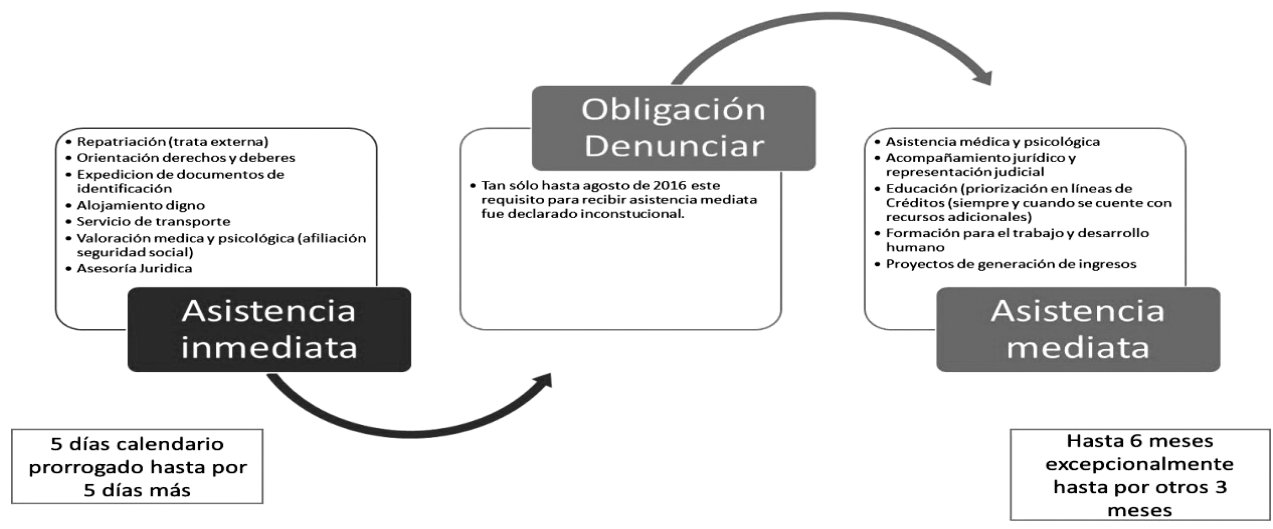

\subsection{El Estado y sus acciones para el restablecimiento de derechos a víctimas de trata de personas}

El Ministerio del Interior, en materia de asistencia y protección a víctimas, tiene algunos instrumentos como el "formato de reporte de caso", por medio del cual se recoge la información de la víctima de trata. Este formato tiene en cuenta los enfoques establecidos en la Estrategia Nacional. Hay un procedimiento definido para la asistencia inmediata y mediata de acuerdo con los principios de igualdad y no discriminación. Además, esta entidad realiza acompañamiento y seguimiento permanentemente en cuanto a las condiciones y estado de la asistencia.

Sin embargo, se considera que existe una debilidad y es la "poca permanencia de las y los funcionarios públicos" (Dirección de Gobierno y Gestión Territorial, Ministerio del Interior, 2016), lo cual ha generado retraso en los procesos.

Con respecto a la información facilitada por las entidades, la Defensoría del Pueblo (2016) reporta que ha atendido de acuerdo con su misión constitucional a $\mathbf{4 2}$ personas que han sufrido la trata desde el 2013 hasta lo que va del 2016, de las cuales 13 son por trabajos forzados o explotación laboral.

Por su parte el Ministerio del Interior informa que en ese mismo periodo ha atendido 88 casos por trabajos forzados (Tabla1). Sin embargo, ya se pueden observar incongruencias tanto en el número de víctimas como en el tipo de asistencia recibida, tan solo el $40 \%$ recibió asistencia mediata. 
Tabla 1. Personas asistidas Ministerio del Interior

\begin{tabular}{lccc}
\hline Año & $\begin{array}{c}\text { Número de víctimas } \\
\text { por trabajos } \\
\text { forzados }\end{array}$ & $\begin{array}{c}\text { Asistencia } \\
\text { inmediata }\end{array}$ & $\begin{array}{c}\text { Asistencia } \\
\text { mediata }\end{array}$ \\
\hline 2013 & 23 & 7 & 12 \\
2014 & 32 & 25 & 16 \\
2015 & 19 & 11 & 7 \\
2016 corte 23 & 5 & 5 & \\
de septiembre & & & $\mathbf{3 5}$ \\
Total & $\mathbf{8 8}$ & $\mathbf{4 8}$ & \\
\hline
\end{tabular}

Fuente:el autor, con base en datos suministrados por Ministerio del Interior.

En el orden distrital, tan solo hasta finales del año 2015 se creó el Comité Distrital para la Lucha contra la Trata de Personas, mediante el Decreto 484 de 2015 y modificado en cuanto a los miembros que lo conforman con el Decreto 583 de 2015, con el deber de articular y coordinar todas las acciones en el marco de la prevención, atención, investigación y judicialización del delito de trata de personas en el Distrito.

Al ser reciente la creación del Comité, hasta este año se está formulando la política pública. Sin embargo, la Secretaría de Gobierno de la Alcaldía Mayor de Bogotá como Secretaría Técnica del Comité informa que está desarrollando acciones a través de mesas técnicas; en cuanto a la asistencia, el Distrito solamente ha realizado asistencia inmediata, ya que según la información facilitada, ninguna de las víctimas es de la ciudad de Bogotá. 
Tabla 2. Servicios ofrecidos por el Distrito

Tipo de servicio

Acciones del Comité Distrital

Repatriación de la víctima extranjera al país de origen

Expedición de la documentación para el retorno

Alojamiento digno

Asistencia médica y psicológica inmediata

Servicio de transporte

Asistencia material

Asistencia jurídica
Acompañamiento y coordinación interinstitucional

Coordinación con la Registraduría Nacional del Estado Civil

Este se brinda de acuerdo a la oferta institucional que existe en el Distrito

Según el Comité Distrital, los 20 hospitales distritales están capacitados para la recepción y atención de víctimas de trata y cuentan con personal profesional como trabajadores sociales y psicólogos

Facilitan el transporte urbano

El distrito le entrega un kit de aseo y un kit de ropa

Este es facilitado por la defensoría del pueblo

Fuente:Secretaría de Gobierno, Alcadía Mayor de Bogotá, respuesta derecho de petición (2016).

Además, se está "planteando una estrategia de persecución para el reconocimiento de territorios y posibles vulneraciones de derechos que puedan constituir el delito de trata" (Secretaría de Gobierno, Alcadía Mayor de Bogotá, 2016). Igualmente, hay un instrumento para la identificación de casos de trata de personas, atendiendo las recomendaciones de los organismos internacionales y nacionales; no obstante, este instrumento básicamente es para la identificación de la explotación sexual. Con lo que ya se ha visto, es que esto promueve el desconocimiento e invisibilización de otras formas de explotación. Para lo cual sería importante que se revise y se diseñe un protocolo que establezca unos criterios generales para reconocer un caso de trata y contemple puntos específicos para identificar el tipo de explotación que ha sufrido la persona. 
Actualmente, el Comité Distrital se encuentra en el proceso de diseño y aprobación de los protocolos de asistencia y aunque considera que tiene un enfoque diferencial, estos se implementan de la misma manera para todas las finalidades de explotación.

La asistencia y protección es el compromiso de la administración distrital desde el Plan de Desarrollo 2016-2020, ya que una de sus prioridades es la lucha contra la trata de personas, razón por la cual el Distrito tiene metas fijadas y hay destinación presupuestal.

Por otro lado, se ha fortalecido la articulación y el compromiso de cada una de las instituciones del Comité, lo que permite trabajar conjuntamente en la atención y protección a las víctimas. Asimismo el Distrito tiene rutas de atención inmediata y mediata con un enfoque poblacional y diferencial, que han sido construidas por los miembros del Comité y en este momento se encuentran en validación por parte de las organizaciones de la sociedad civil.

Finalmente, las víctimas registradas entre el año 2013 y el 2015 han sido 83, de las cuales un $29 \%$ ha sido por trabajos forzados y un $13 \%$ por matrimonio servil. Ya para el 2016 se han atendido 13 víctimas, de las cuales 5 han sido por trabajos forzados (tres hombres y dos mujeres).

\subsection{Las acciones realizadas por el Estado para el restablecimiento de derechos a víctimas de trata de personas: mirada desde las organizaciones de la sociedad civil}

A la pregunta, si los enfoques (de derechos, género, diferencial) planteados en la Estrategia Nacional se tienen en cuenta a la hora de identificar, asistir y proteger a una persona víctima de trata, el $100 \%$ de los entrevistados afirma que para el Estado estos no son prioritarios y tan solo están definidos en el papel. "Realmente no se tiene en cuenta sino que se tiene un protocolo de manera general para la atención de las víctimas (...) el año pasado atendimos una indígena y fue exactamente igual" (experto, comunicación personal, 30 de septiembre de 2016).

Además se afirma que para el Estado no es prioridad la atención diferenciada: “... La ruta que tienen los comités de alguna manera tampoco permite que ellos puedan tener esa atención diferenciada, particular... es como muy difícil" (B. Pedraza, comunicación personal, 26 de septiembre de 2016). Por lo que Óscar Gómez, de Fundación Esperanza, considera que esto se debe además porque la política pública no está orientada desde un enfoque de derechos humanos, sino de política criminal: 
El enfoque de la política pública en Colombia nunca, nunca ha sido de derechos humanos, ha sido un enfoque de política criminal y cuando el enfoque de política criminal es lo que prima...la relación del Estado con la víctima es funcional... le interesa la víctima que denuncia, que sea testigo, que acompañe o apoye al Estado en todos los mecanismos de política criminal... jamás la víctima ha estado en el centro de la política pública. (Gómez, 2016).

Es unánime la percepción de las organizaciones de la sociedad civil frente al accionar del Comité Interinstitucional de Lucha contra la Trata de Personas. Los resultados encontrados evidencian las falencias que existen en el Estado para garantizar el restablecimiento de derechos a las personas que han vivido la trata. "Lo que pasa es que el Estado le hace la atención a unas víctimas, no a todas... entonces no hay como la garantía, ahí es donde entramos las organizaciones a atender a todo mundo, las organizaciones nunca rechazamos a nadie" (Pedraza, 2016).

Con respecto al Decreto 1069 de 2014, que establece acciones para la asistencia y protección a víctimas y fija unos tiempos de 5 hasta 10 días para la asistencia inmediata (asistencia de urgencia) y de 3 hasta 6 meses para la asistencia mediata, a los entrevistados se les preguntaba si esos tiempos permitían el restablecimiento de derechos, a lo que respondían que "en cuanto a la atención inmediata me parece que se acercan, en la atención mediata no, empezando porque los tiempos de ellas son muy distintos a los tiempos nuestros... los tiempos no corresponden a la realidad" (A. Bravo, comunicación personal, 29 de septiembre de 2016).

No, no, no, o sea es que ni siquiera la víctima a la que le haya ido "más bien"... esos tiempos no sirven para nada, si no hay un proceso de atención desde el mismo momento en que llegan, miren ni siquiera se necesitan años, una víctima bien atendida en un año, podría estar con los derechos restablecidos. (J. Toro, comunicación personal, 21 de septiembre de 2016).

Definitivamente, por experiencia de las organizaciones, es importante analizar cada caso para definir qué tipo de necesidades tiene la víctima y lograr su recuperación física y psicológica, además de retomar su proyecto de vida,

Lo que pasa es que es muy particular cada caso...nosotros trabajamos cada caso desde ellas, sobre su particularidad, hay unas que vemos que en los seis meses no alcanza...porque tiene una situación y ha vivido cosas tan difíciles que los seis meses nos lleva solo en la parte de la recuperación emocional... si ella no está recuperada no podemos empezar los otros procesos, pero en cambio hay algunas que al mes... tienen todo claro. (Pedraza, 2016). 
En materia de protección, la persona que ha vivido la trata es considerada mas bien como testigo y en esa medida puede recibir o no protección por parte de la Fiscalía,

... las víctimas tienen que aparte de todo aportar pruebas muy grandes en un lapso de 3 meses para mantenerse en el programa por otro tiempo, entonces, si la persona con la información que dan, en 3 meses hacen una captura puede continuar, si no, dicen pues la información que usted nos ha dado no nos ha servido. (Experto, 2016).

En este mismo sentido, tanto de la Fundación Jhonatan como de la Corporación Espacios de Mujer, expresan que:

...Con el programa de protección, se la iban a llevar del país pero tenía que dejar al hijo, entonces ella renunció, jcómo me voy a ir y con quién dejo al niño! Ella está en otro municipio, pero no accedió al programa, ¿cómo separar a la familia, y el niño qué? entonces de resto cero, absolutamente negativo. (Toro, 2016)

Es difícil, nosotros hemos tenido muchos casos que han solicitado protección, sobre todo un caso de trata externa, hicieron la denuncia, pidieron la protección y nada, ellas se han tenido que cambiar cada mes de casa... una víctima recibió unas puñaladas de su captor... ella había denunciado, fue con la orden de...protección a la policía y el policía le decía -es que yo no puedo ponerle un policía a todos los que denuncian, ponga usted cámaras en su casa y cuídese- y a otra le tocó recurrir a los grupos al margen de la ley, a las bandas del barrio para que los de la banda espantaran a los otros.. Fue la única manera. (Pedraza, 2016).

En cuanto a las debilidades que las organizaciones perciben por parte del Estado para la asistencia y protección a víctimas de trata, principalmente con relación a la capacidad institucional: a) son escasos los recursos económicos que se destinan para la asistencia, además el desconocimiento de la problemática y el cambio de funcionarios no permite que se active la ruta y se restablezcan los derechos. b) Existe una cierta discrecionalidad a la hora de identificar y atender a las víctimas. c) No hay una atención diferenciada de acuerdo con el tipo de explotación sufrida. d) La asistencia está en manos de las organizaciones. e) Es muy débil la articulación interinstitucional (entre las entidades que conforman los comités y entre comités). f) No se realiza seguimiento y evaluación al tipo de asistencia que brindan las organizaciones de la sociedad civil. g) No tienen una política pública con enfoque de derechos humanos para la asistencia y protección. 
Ahora, con respecto a la obligación del Estado de garantizar los derechos a la salud y educación, los entrevistados coinciden en que hay serias deficiencias. En primer lugar, la persona víctima, según el nivel de $\operatorname{Sisbén}^{3}$, tiene que pagar una cuota moderadora.

Si usted revisa el Decreto y la Ley, no es específico que las víctimas tengan acceso a una EPS subsidiada sino a un SISBEN, que dependiendo del estrato donde vivía la persona va a ser su atención pagando un porcentaje, no hay asistencia gratuita. (C. Quintero, comunicación personal, 20 de septiembre de 2016).

En segundo lugar, la atención en salud (consultas) es un poco más asequible cuando se ha sufrido la explotación sexual; no obstante, para la explotación laboral, que la víctima pueda ser atendida es una proeza, igual que para recibir atención especializada, "conseguir una cita de psiquiatría es todo un calvario" (experto, 2016). Además, no se tienen protocolos para la atención y el personal no está informado para este tipo de atención.

Ya en materia educativa, la oferta institucional está a cargo del SENA, el cual brinda orientación y algunos cursos que no están acordes con las capacidades y los intereses de las víctimas.

Por otro lado, en la Tabla 3 se refleja lo que las organizaciones han realizado en materia de asistencia a víctimas de trata y las dificultades o barreras que han encontrado en el momento de requerir el apoyo o ayuda del Estado.

3 Este nivel se lo asigna de acuerdo con la visita que realizan en donde la persona se encuentra alojada y en varios casos quedan en un nivel muy alto. 
Tabla 3. Número de víctimas y dificultades en la asistencia

\begin{tabular}{|c|c|c|c|c|}
\hline Organización & $\begin{array}{l}\text { Cuántas víctimas } \\
\text { han sido asistidas }\end{array}$ & $\begin{array}{c}\text { ¿Cuántas } \\
\text { por trabajos } \\
\text { forzados? }\end{array}$ & $\begin{array}{l}\text { ¿Qué tipo de } \\
\text { asistencia han } \\
\text { recibido? }\end{array}$ & $\begin{array}{c}\text { ¿Qué dificultades } \\
\text { ha encontrado } \\
\text { en la ruta de } \\
\text { asistencia? }\end{array}$ \\
\hline $\begin{array}{l}\text { Fundación } \\
\text { Marcela } \\
\text { Loaiza }\end{array}$ & $\begin{array}{l}\text { Por promedio } \\
\text { anual entre } 10-12 \\
\text { víctimas (desde } \\
\text { hace } 5 \text { años). }\end{array}$ & $\begin{array}{l}20 \% \text { de las } \\
\text { personas } \\
\text { que reciben } \\
\text { en la } \\
\text { Fundación }\end{array}$ & $\begin{array}{l}\text { Atención } \\
\text { psicológica, } \\
\text { acompañamiento } \\
\text { en trabajo social, } \\
\text { orientación } \\
\text { pedagógica y } \\
\text { formativa y apoyo } \\
\text { en asistencia a } \\
\text { menores hijos de } \\
\text { víctimas. }\end{array}$ & $\begin{array}{l}\text { Es muy difícil que } \\
\text { las instituciones } \\
\text { realicen } \\
\text { tratamientos } \\
\text { y exámenes } \\
\text { en salud. La } \\
\text { respuesta es } \\
\text { muy débil. La } \\
\text { orientación del } \\
\text { SENA no está } \\
\text { acorde con los } \\
\text { intereses de las } \\
\text { víctimas. }\end{array}$ \\
\hline $\begin{array}{l}\text { Fundación } \\
\text { Esperanza }\end{array}$ & $\begin{array}{l}\text { No tienen la } \\
\text { cifra exacta, } \\
\text { aunque uno de } \\
\text { los objetivos } \\
\text { principales de la } \\
\text { organización ha } \\
\text { sido la asistencia } \\
\text { en } 20 \text { años de } \\
\text { historia. }\end{array}$ & $\begin{array}{l}\text { Sí han } \\
\text { atendido } \\
\text { personas } \\
\text { víctimas } \\
\text { por trabajos } \\
\text { forzados, } \\
\text { explotación } \\
\text { laboral, } \\
\text { servidum- } \\
\text { bre... }\end{array}$ & & \\
\hline $\begin{array}{l}\text { Fundación } \\
\text { Jhonatan }\end{array}$ & $\begin{array}{l}50 \text { personas } \\
\text { víctimas entre } \\
2009-2016 .\end{array}$ & $\begin{array}{l}\text { Dos } \\
\text { personas: } \\
\text { una mujer } \\
\text { víctima en } \\
\text { Perú y un } \\
\text { hombre } \\
\text { explotado } \\
\text { en el } \\
\text { Ecuador. }\end{array}$ & $\begin{array}{l}\text { La asistencia se } \\
\text { brinda desde el } \\
\text { acompañamiento, } \\
\text { con casos exitosos } \\
\text { en la inserción } \\
\text { laboral y en el } \\
\text { ámbito educativo a } \\
\text { través de un equipo } \\
\text { interdisciplinario. }\end{array}$ & $\begin{array}{l}\text { La atención } \\
\text { es mínima, el } \\
\text { Estado tiene a } \\
\text { las víctimas en } \\
\text { un completo } \\
\text { abandono, } \\
\text { carencia de } \\
\text { recursos } \\
\text { económicos. }\end{array}$ \\
\hline $\begin{array}{l}\text { Corporación } \\
\text { Espacios de } \\
\text { Mujer }\end{array}$ & $\begin{array}{l}\text { De } 120 \text { a } 130 \\
\text { aproximadamente. }\end{array}$ & & $\begin{array}{l}\text { Acompañamiento } \\
\text { psicosocial, } \\
\text { se cuenta con } \\
\text { protocolos de } \\
\text { atención. }\end{array}$ & $\begin{array}{l}\text { Rotación de } \\
\text { funcionarios, lo } \\
\text { que no permite } \\
\text { que se active la } \\
\text { ruta. }\end{array}$ \\
\hline
\end{tabular}




\begin{tabular}{|c|c|c|c|c|}
\hline Organización & $\begin{array}{l}\text { Cuántas víctimas } \\
\text { han sido asistidas }\end{array}$ & $\begin{array}{l}\text { ¿Cuántas } \\
\text { por trabajos } \\
\text { forzados? }\end{array}$ & $\begin{array}{l}\text { ¿Qué tipo de } \\
\text { asistencia han } \\
\text { recibido? }\end{array}$ & $\begin{array}{c}\text { ¿Qué dificultades } \\
\text { ha encontrado } \\
\text { en la ruta de } \\
\text { asistencia? }\end{array}$ \\
\hline $\begin{array}{l}\text { Corporación } \\
\text { Anne Frank }\end{array}$ & $\begin{array}{l}\text { Acompañamiento } \\
\text { en el } 2015 \text { a } \\
14 \text { procesos de } \\
\text { generación de } \\
\text { ingresos. }\end{array}$ & $\begin{array}{l}10 \text { personas } \\
\text { por } \\
\text { explotación } \\
\text { laboral en } \\
\text { Argentina } \\
\text { y por el } \\
\text { microtráfico } \\
\text { en el Bronx- } \\
\text { Bogotá. }\end{array}$ & $\begin{array}{l}\text { Acompañamiento } \\
\text { psicosocial a través } \\
\text { de la Universidad } \\
\text { Konrad Lorenz } \\
\text { y atención } \\
\text { jurídica desde la } \\
\text { Universidad Jorge } \\
\text { Tadeo Lozano. }\end{array}$ & $\begin{array}{l}\text { Deficiencia en la } \\
\text { atención en salud, } \\
\text { los tiempos son } \\
\text { una limitación. }\end{array}$ \\
\hline Experto & $\begin{array}{l}\text { Por año un } \\
\text { promedio de } 30 \\
\text { personas desde el } \\
2012 \text {. }\end{array}$ & $\begin{array}{l}\text { Un } 50 \% \text { de } \\
\text { las personas } \\
\text { asistidas un } \\
30 \% \text { son } \\
\text { hombres. }\end{array}$ & $\begin{array}{l}\text { Se les brinda } \\
\text { la asistencia de } \\
\text { alojamiento, } \\
\text { incluyendo } \\
\text { alimentación, } \\
\text { trabajo psicosocial, } \\
\text { gestión en salud, } \\
\text { educación cuando } \\
\text { se puede gestionar, } \\
\text { documentación, } \\
\text { traslados, } \\
\text { acompañamiento } \\
\text { dependiendo del } \\
\text { caso }\end{array}$ & $\begin{array}{l}\text { Ha pasado de } \\
\text { todo, a veces } \\
\text { los recursos los } \\
\text { recursos que } \\
\text { se necesitan } \\
\text { dependen de } \\
\text { la voluntad del } \\
\text { funcionario. En } \\
\text { ocasiones adquirir } \\
\text { una cita para } \\
\text { psiquiatría es un } \\
\text { calvario, cuando } \\
\text { es por explotación } \\
\text { laboral es peor. }\end{array}$ \\
\hline
\end{tabular}

Finalmente, frente a la trata laboral, con las respuestas se corrobora que es un tipo de explotación que en Colombia aún no se ha investigado, aunque se han hecho algunos esfuerzos.

Tiene su origen en la falta de información y la falta de regulación de las empresas, porque la empresa contratante en Colombia en toda la cadena de valor tiene muchísimos contratistas y se exonera de responsabilidad en el proceso de contratación cuando subcontratan... y no hay forma de monitorearlo, estamos ante un delito invisible... y de una magnitud muchísima más alta. (Bravo, 2016).

Se cree que si se empieza a visibilizar esa forma de trata se podrían esperar innumerables casos para los que el Estado no está preparado. Además, en muchas ocasiones las personas no consideran que hayan sido víctimas de trata laboral, debido a la falta de conocimiento. 


\subsection{El tipo de asistencia que recibió un sobreviviente de la trata laboral}

Se entrevistó a un hombre colombiano, mayor de edad, que vivió la explotación en otro país (septiembre 2009-enero 2011).

En cuanto a salud, le realizaron chequeos médicos muy simples, pero no se llevó a cabo una atención especializada para poder recuperarse totalmente. Tanto él como su familia recibieron por parte del gobierno un pre-Sisbén; sin embargo, quedaron en un nivel muy alto, por lo que debían cancelar el 30\% de cualquier tipo de atención médica; es decir, que si no contaban con los recursos, pues difícilmente podían acceder a esta.

Por parte del Estado nunca recibió atención especializada para recuperarse de sus lesiones en la rodilla. Actualmente, por sus propios medios está haciendo el esfuerzo para ser atendido y recuperarse totalmente, ya que de él depende su familia.

En cuanto al tema de lo que tiene que ver con la salud, yo pienso que es un tema que debe ser revisado porque no hay una política específica para el tratamiento especial de la persona que sufre este flagelo. [...] la persona que ha sido víctima de trata de personas debería tener una asistencia especializada gratuita por parte del gobierno. Pero en este momento todavía eso no es posible, se brinda una pequeña asistencia en todo lo que tiene que ver lo de salud pero no es una asistencia que cubra las necesidades totales de las personas que han sufrido este flagelo. (Anónimo, comunicación personal, 20 de septiembre de 2016).

Por otro lado, él enfatiza en que algunos de los subsidios que recibió -como el de transporte y alimentación- fueron de gran ayuda para sobrellevar la situación. No obstante, él resalta que lo que incita a que se cometa este tipo de delitos es la impunidad,

Es lamentable decirlo pero para la fiscalía, supuestamente no hubo ningún tipo de delito en mi caso. Para ellos se presentaron... situaciones que no fueron agradables... No hay un personal especializado de trata de personas en la fiscalía; entonces ellos toman el caso a su manera y entre más rápido puedan deshacerse de él, mejor, porque tenemos muchos, muchos casos... como te digo fui trasladado, fui acogido, el empresario se lucró conmigo, me retuvieron los documentos en un momento dado porque temían que podía salir del país, mi derecho de locomoción me lo restringieron, recibí amenazas...y para ellos no fue un delito, lo que me parece a mí muy sorprendente. (Anónimo, 2016). 
Ya lleva tres años en Colombia después de lo ocurrido y no ha podido ubicarse laboralmente, no tiene una carrera profesional y tampoco se ha podido recuperar físicamente. Aunque se considera un sobreviviente porque ha podido levantarse y emprender un nuevo desafío; actualmente está generando procesos de prevención en trata de personas, ya que quiere mostrar la realidad que se vive y evitar que otras personas sean víctimas de trata.

Él resalta que es importante tener en cuenta todas las formas de explotación y garantizar ayudas en vivienda, educación, salud y todo lo que tiene que ver con el empoderamiento. Es posibilitar que la persona no vuelva a ser víctima de trata y, en este sentido, es importante tener una política pública que garantice el restablecimiento de derechos. "En la vida todo tiene un propósito... entonces dar, todo lo que yo más pueda, a esas personas para evitar que ellas vivan lo que yo tuve que vivir, eso me reconforta muchísimo y esto me hace muy feliz". (Anónimo, 2016).

\section{Conclusiones}

En Colombia, los programas de lucha contra la trata de personas tienen un enfoque criminal, en el que la víctima es vista como testigo y coaccionada a denunciar para que sus derechos puedan ser restablecidos, generando mayor daño. No existe un programa integral de asistencia y protección.

Con respecto a la información facilitada por las entidades, se refleja que no hay uniformidad en los casos; la Defensoría del Pueblo (2016) ha atendido a 42 personas que han sufrido la trata desde el 2013 hasta lo que va del 2016, de las cuales 13 son por trabajos forzados o explotación laboral. Por su parte, el Ministerio del Interior informa que en ese mismo periodo ha atendido 88 casos por trabajos forzados (Tabla 1), lo que lleva a concluir que: a) son pocas las personas víctimas que tienen acompañamiento jurídico, en este caso un $15 \%$, b) la mayoría de las personas recibió tan solo asistencia inmediata, tal vez por el condicionamiento de denuncia para recibir asistencia mediata que existía hasta agosto de 2016; c) no hay correlación entre el número de casos y el número de personas que fueron asistidas, lo que significa que es muy poco probable que haya un restablecimiento de derechos.

Por otro lado, a partir del Decreto 1069 de 2014, recogido por el Decreto 1066 del 2015 (Decreto Único Reglamentario del Sector Administrativo del Interior), la asistencia a víctimas está a cargo de los comités municipales y distritales, y en el caso de que no haya comités municipales, esta asistencia la hará el comité 
departamental. No obstante, el Decreto establece que dicha asistencia se debe realizar de forma coordinada y articulada a partir de la activación de la ruta por parte del Ministerio del Interior; es decir, que la debida asistencia que se le brinda a la víctima si y solo si se puede garantizar si hay una efectiva articulación entre las instituciones. Los resultados reflejan que no ha sido posible.

Es claro que el obstáculo mayor se encuentra en el momento de requerir el apoyo y coordinación de las instituciones para la asistencia; es decir, que la barrera principal se presenta cuando se requiere una atención específica, como lo reflejan las organizaciones, en materia de salud y educación especialmente.

Igualmente, el cambio de funcionarios y el desconocimiento acerca de la problemática han dificultado la asistencia y el restablecimiento de derechos, lo cual conduce a una posible revictimización. Lo más preocupante es que al no haber lineamientos claros para la asistencia, la discrecionalidad de las entidades para determinar los criterios con los cuales se atiende o no a una víctima, están generando casos de discriminación y vulneración a los derechos fundamentales.

Teniendo en cuenta que el requisito de denuncia para recibir asistencia mediata se ha declarado inconstitucional, es necesario revisar y ajustar el Decreto 1069 de 2014, en la medida que no se justifica una división entre asistencia inmediata y mediata. Esta debe estar orientada a un proceso de atención permanente, que no debe estar supeditado a unos tiempos sino a lograr el restablecimiento de derechos.

En cuanto a la protección de las víctimas, las organizaciones han manifestado: primero, la necesidad de que exista un protocolo de protección específicamente para personas que han vivido la trata, ya que actualmente el programa de protección a víctimas y testigos de la Fiscalía está diseñado para víctimas primordialmente del conflicto armado. Segundo, que estos lineamientos deben tener la facilidad de adecuarse a cada caso en particular. No se puede restringir el concepto de protección a las medidas de seguridad que pueda o no facilitar la Fiscalía.

Otro aspecto que reflejan los resultados es que definitivamente no hay rutas diferenciales; se maneja una única ruta de atención dedicada especialmente a la explotación sexual, sin considerar la forma de explotación.

Algunos coinciden en que no se puede hablar de un protocolo único de atención, ya que los casos son muy diferentes, estos deben ser adaptados a cada situación de acuerdo con la forma de explotación que sufrió. 
Cada organización, en la práctica, ha venido estableciendo algunos lineamientos para la asistencia a víctimas de otras formas de explotación, que valdría la pena conocer, compartir y retroalimentar.

En lo que respecta a la trata laboral, se colige que es muy deficiente el trabajo que se ha hecho para asistir a las víctimas de esta forma explotación. No se sabe con certeza la magnitud del problema. No hay claridad frente a la conceptualización de esta forma de explotación, por lo cual, también se dificultan las acciones para informar acerca de esta problemática.

Además, se percibe que cada organización hace su trabajo de acuerdo con lo que cree es lo más adecuado; sin embargo, en esa articulación se deberían generar procesos para unificar criterios, rutas de atención y efectuar gestiones ante las instituciones para la superación de las situaciones que limitan los derechos de las víctimas.

Finalmente, las organizaciones consideran que el acercamiento a la víctima no debe partir de juicios morales, sino que debe ser vista de acuerdo con sus necesidades y que requiere apoyo y protección. Es importante tener capacidad de escucha y realizar acompañamiento a esas necesidades sin imponer criterios o ideologías del operador. La víctima debe ser considerada como tal, como un ser humano con unas necesidades específicas y es ella la que va indicando los términos, no se le pueden imponer; es necesario brindarle a la persona víctima de trata, espacios para la reflexión; además, la educación debe propender a la reintegración integral, facilitando acceso a diversas ofertas laborales (estas siempre deben estar basadas en las necesidades de la víctima). Igualmente, se rescata la experiencia de trabajo de forma articulada Estado-organizaciones sociales, organizaciones internacionales e Iglesia, ya que esto garantiza que efectivamente se pueda brindar la atención de forma adecuada.

\section{Referencias}

Agamben, G. (2006). Lo abierto. El hombre y el animal (1 ed.). En F. Lebenglik (Ed.). F. C. Castro (Trad.). Buenos Aires: Adriana Hidalgo.

Alarcón, N. (2016, 20 de sep.). Asistencia y protección a víctimas de trata de personas en Colombia. Entrevista.

Alcaldía Mayor de Bogotá (2015, 24 de dic.). Decreto 583. Por medio del cual se modifica el Decreto Distrital 484 de 2015. Recuperado de: http://www. alcaldiabogota.gov.co/sisjur/normas/Norma1.jsp?i=64223 
Alcaldía Mayor de Bogotá. (2015, 25 de nov.). Decreto 484. Por medio del cual se crea el Comité Distrital para la Lucha contra la Trata de Personas de Bogotá, D.C. y otras disposiciones. Recuperado de: http://www.alcaldiabogota.gov.co/ sisjur/normas/Norma1.jsp?i=63863

Alianza Global contra la Trata de Mujeres-GAATW. (2015). Hacia una mayor rendición de cuentas/responsabilidad; monitoreo participativo de iniciativas contra la trata de personas. Recuperado de https://fundacionrenacer.org/wpcontent/uploads/2015/08/informe-regional-lac-gaatw.pdf

Alto Comisionado de las Naciones para los Refugiados -ACNUR-. (2009). Identificación y derivación de las personas víctimas de trata a los procedimientos para la determinación de las necesidades de protección internacional. Recuperado de: http://www.refworld.org/pdfid/4af98c4d2.pdf

Asamblea General de Naciones Unidas (1948). Declaración Universal de Derechos Humanos. Recuperado de: http://www.hchr.org.co/documentoseinformes/ documentos/carceles/1_Universales/B\%E1sicos/1_Generales_DH/1_ Declaracion_Universal_DH.pdf

Asamblea General de Naciones Unidas (1985, 29 de nov.). Declaración sobre los principios fundamentales de justicia para las víctimas de delitos y del abuso de poder, Resolución 40/34. Recuperado de: http://www.ohchr.org/SP/ ProfessionalInterest/Pages/VictimsOfCrimeAndAbuseOfPower.aspx

Asamblea General de Naciones Unidas (2000). Convención de las Naciones Unidas contra la Delincuencia Organizada Transnacional.Recuperado de https://www.unodc.org/documents/treaties/UNTOC/Publications/TOC\%20 Convention/TOCebook-s.pdf

Asamblea General de Naciones Unidas (1979). Convención sobre la Eliminación de todas las Formas de Discriminación contra la Mujer. Recuperado de: http://www.unicef.org/panama/spanish/MujeresCo_web.pdf

Asamblea General de Naciones Unidas. (2014, 18 de dic.). Resolución 69/149. A/ RES/69/149. Recuperado de: http://www.acnur.org/t3/fileadmin/Documentos/ BDL/2015/9907.pdf

Asamblea Nacional Constituyente (1991). Constitución Política de Colombia. Bogotá: Imprenta Nacional. 
Bernal, F. (2006). Análisis y aplicabilidad de la Ley 985 de 2005, por medio de la cual se adoptan medidas contra la trata de personas y normas para la atención y protección de las víctimas de la misma. Recuperado de: http:// cdim.esap.edu.co/BancoMedios/Documentos\%20PDF/an\%C3\%A1lisis\%20 y\%20aplicabilidad\%20de\%20la\%20ley\%20985\%20de\%202005.pdf

Bernal, M. M. (2010). Modelos de atención dirigidos a mujeres en situacion de trata de personas: una lectura crítica desde la perspectiva de género. Recuperado de: http://www.bdigital.unal.edu.co/2740/1/489024.2010.pdf

Cardozo, S. M. (2006). Análisis del papel del Estado colombiano en el marco del discurso de la trata de mujeres y su relación con la explotación sexual y la prostitución femenina. Recuperado de: http://cienciagora.com.co/imgs2012/ imagenes/Tesis_Sandra_Cardozo.pdf

Cardozo, S. M. (2010). Lectura teórica sobre la inclusión de la perspectiva de género en las políticas públicas para combatir la trata de personas en Colombia. Recuperado de: http://repository.urosario.edu.co/handle/10336/2118

Centro de Pensamiento sobre Trata de Personas. (2016). Implementación de la Política pública contra la trata de personas en Colombia 2010-2014. Bogotá. Recuperado de https://cptratadepersonas.files.wordpress.com/2016/03/ informe-cptp-2015.pdf

Conferencia General de la Organización Internacional del Trabajo (1930, 28 de junio). Convenio sobre el Trabajo Forzoso, 29. Recuperado de: http://www. ilo.org/dyn/normlex/es/f?p=NORMLEXPUB:12100:0::NO::P12100_ILO_ CODE:C029

Conferencia Mundial de los Derechos Humanos. (1993). Declaración y Programa de Acción de Viena. Recuperado de: http://www.ohchr.org/Documents/Events/ OHCHR20/VDPA_booklet_Spanish.pdf

Congreso de la República de Colombia. (2000, 24 de jul.). Ley 599 de 2000, por la cual se expide el Código Penal. Recuperado de: http://www.alcaldiabogota. gov.co/sisjur/normas/Norma1.jsp?i=6388

Congreso de la República de Colombia. (2005, 6 de ago.). Ley 985 de 2005, por medio de la cual se adoptan medidas contra la trata de personas y normas para la atención y protección de las víctimas de la misma. Bogotá: Imprenta Nacional. 
Congreso de la República de Colombia. (2003, 13 de mar.). Ley 800 de 2003. Recuperado de https://www.oas.org/dil/esp/Convencion_ONU_trata_de_ personas_Colombia.pdf

Corte Constitucional. (2012, 12 de dic.). Sentencia T-1078-12.M.P. J. I. Pretelt. Recuperado de: http://www.corteconstitucional.gov.co/ relatoria/2012/T-1078-12.htm

Corte Constitucional. (2016, 31 de ago.). Sentencia C-470-2016. M.P. G. E. Mendoza Martelo.

Cortina, A. \& Martínez, E. (2008). Ética. Madrid: Akal.

Defensoría del Pueblo. (2016, 29 de sep.). Respuesta a derecho de petición 201600367828. Bogotá.

Departamento de Estado de los Estados Unidos. (2014). Trafficking in Persons Report.

Departamento de Estado de los Estados Unidos. (2015). Trafficking in Persons Report. Retrieved from http://www.state.gov/documents/organization/246072. pdf

Departamento de Estado de los Estados Unidos. (2016). Trafficking in Persons Report. Retrieved from http://www.state.gov/documents/organization/245365. pdf

Diario Uno. (17 de agosto de 2015). Pidieron una indagatoria al presidente de Falabella. Diariouno.com.ar. Recuperado de: http:/www.diariouno.com.ar/ pais/Pidieron-una-indagatoria-al-presidente-de-Falabella-Argentina-por-tratade-personas-20150817-0063.html

Dirección de Gobierno y Gestión Territorial, Ministerio del Interior. (2015, 2 de jul.). Respuesta EXTEMI15-0028154. Bogotá.

Dirección de Gobierno y Gestión Territorial, Ministerio del Interior. (2016, 11 de oct.). Respuesta derecho de petición EXTMI16-0049769. Bogotá.

Federación Internacional de Sociedades de la Cruz Roja y de la Media Luna Roja. (2011). Guía para el seguimiento y la evaluación de proyectos y programas. Ginebra. Recuperado de: http://www.ifrc.org/Global/Publications/ monitoring/1220500-Monitoring-and-Evaluation-guide-SP.pdf 
Fiscalía General de la Nación. (2015). Informe de gestión 2014-2015. Bogotá: Imprenta Nacional de Colombia. Recuperado de: http://www.fiscalia.gov.co/ en/wp-content/uploads/212419-Gesti\%C3\%B3n-2014-2015-final-11.pdf

Giménez-Salina, A., Susaj, G. \& Requena, L. (2009). La dimensión laboral de la trata de personas en España. Revista Electrónica de Ciencia Penal y Criminología, 4(1), 25. Recuperado de: http://criminet.ugr.es/recpc/11/recpc11-04.pdf

Grüner, E. (2011). Los avatares del pensamiento crítico, hoy por hoy. En E. Grüner, Nuestra América y el pensar crítico: fragmentos de pensamiento crítico de Latinoamérica y el Caribe (p. 368). Buenos Aires: Consejo Latinoamericano de Ciencias Sociales -CLACSO-.

Hurtado, M. \& Iranzo, A. (. (2015). Miradas críticas sobre la trata de seres humanos. Diálogos académicos en construcción. Bogota: Ediciones Uniandes. doi:http://dx.doi.org/10.7440/2015.04

Llain, S. \& Guzmán, S. P. (2014). La protección internacional de los refugiados víctimas de trata de personas. Revista de Derecho, (42), 284-311. doi:http:// dx.doi.org/10.14482/dere.42.6789

Naciones Unidas, Derechos Humanos (2016). Observaciones finales sobre el séptimo informe periódico de Colombia. Recuperado de: http://tbinternet. ohchr.org/_layouts/treatybodyexternal/Download.aspx?symbolno=CCPR/C/ $\mathrm{COL} / \mathrm{CO} / 7 \&$ Lang=en

Oficina del Alto Comisionado de las Naciones Unidas para los Derechos Humanos. (2014). Los Derechos Humanos y la Trata de Personas, Folleto Informativo $N^{\circ}$ 13. Obtenido de: http://www.ohchr.org/Documents/Publications/FS36 sp.pdf

Organización de los Estados Americanos. (1969). Convención Americana sobre Derechos Humanos. Recuperado de: http://www.oas.org/dil/esp/tratados B32_Convencion_Americana_sobre_Derechos_Humanos.pdf

Organización de los Estados Americanos (1985, 9 de dic.). Convención Interamericana para prevenir y sancionar la tortura. Recuperado de: http://www.oas.org/es/cidh/mandato/documentos-basicos/convencioninteramericana-prevenir-sancionar-tortura.pdf 
Organización de los Estados Americanos. (1994, 9 de jun.). Convención Interamericana para Prevenir, Sancionar y Erradicar la Violencia Contra la Mujer.

Organización Internacional para las Migraciones. (2015, 30 de julio). En el Día Mundial contra la Trata de Personas, la OIM insta a un compromiso renovado contra la explotación y la trata. Recuperado de: http://www.oim.org.co/ noticias/44-trata-de-personas/3543-en-el-dia-mundial-contra-la-trata-depersonas-la-oim-insta-a-un-compromiso-renovado-contra-la-explotacion-yla-trata.html

Pacecca, M. I. (2011). Trabajo, explotación laboral, trata de personas. Categorías en cuestión en las trayectorias migratorias. Revista Interdisciplinar da Mobilidade Humana, 19(37), 147-174. Recuperado de: http://www.csem.org.br/remhu/ index.php/remhu/article/view/281/256

Papacchini, A. (1998). Ética y Derechos Humanos. Bogotá: Común Presencia Editores.

Pedraza, B. (26 de septiembre de 2016). Asistencia y protección a víctimas de trata de personas en Colombia. (N. Alarcón M., Entrevistador).

Presidente de la República de Colombia. (2008, 19 de dic.). Decreto 4786 de 2008, por el cual se adopta la Estrategia Nacional Integral contra la Trata de Personas. Recuperado de: http://www.alcaldiabogota.gov.co/sisjur/normas/ Norma1.jsp?i $=34645$

Presidente de la República de Colombia. (2011, 11 de ago.). Decreto 2893 de 2011, por el cual se modifican los objetivos, la estructura orgánica y funciones del Ministerio. Recuperado de: http://www.mininterior.gov.co/sites/default/files/ upload/decreto_2893_de_11072011.pdf

Presidente de la República de Colombia. (2014, 12 de junio). Decreto 1069 de 2014, por el cual se reglamenta parcialmente la Ley 9S5 de 2005. Recuperado de: http://wsp.presidencia.gov.co/Normativa/Decretos/2014/Documents/ JUNIO/12/DECRETO\%201069\%20DEL\%2012\%20DE\%20JUNIO\%20 DE\%202014.pdf 
Presidente de la República de Colombia. (2015, 26 de mayo). Decreto 1066 de 2015, por medio del cual se expide el Decreto Único Reglamentario del Sector. Recuperado de: http://www.mininterior.gov.co/sites/default/files/ decreto_1066_de_2015_unico_reglamentario_del_sector_administrativo_ del_interior.pdf

Presidente de la República de Colombia. (2016, 24 de junio). Decreto 1036 de 2016, por el cual se adiciona un capítulo al Libro 2, Parte 2, Título 3 del Decreto No. 1066 de 2016, Decreto Único Reglamentario del Sector Interior, con el fin de adoptar la Estrategia Nacional para la Lucha contra la Trata de Personas, 2016-2018. Recuperado de: http://es.presidencia.gov.co/normativa/ normativa/DECRETO\%201036\%20DEL\%2024\%20DE\%20JUNIO\%20 DE\%202016.pdf

Requena, L., Giménez, A. \& De Juan, M. (2009, mayo-junio). La trata de personas para su explotación laboral: análisis de la situación en España. Boletín Criminológico Instituto Andaluz Interunivesitario de Criminología, (114), 1-4. Recuperado de: http://www.boletincriminologico.uma.es/boletines/114. pdf

Secretaría de Gobierno, Alcadía Mayor de Bogotá. (2016, 30 de sep.). Respuesta derecho de petición 20166240365112. Bogotá. 